\title{
K-Ortalamalar Kümeleme Yöntemi Kullanılarak ALS Hastalarında Dikkatin Olaya İlişkin Potansiyel Sinyalleri İle İncelenmesi ${ }^{* *}$
}

\author{
Firat Orhanbulucu $^{1 * *}$, Fatma Latifoğlu ${ }^{2}$, Abdullah Baş $^{3}$ \\ ${ }^{1}$ İnönü Üniversitesi, Mühendislik Fakültesi, Biyomedikal Mühendisliği Bölümü, Malatya, Türkiye (ORCID: 0000-0003-4558-9667) \\ ${ }^{2}$ Erciyes Üniversitesi, Mühendislik Fakültesi, Biyomedikal Mühendisliği Bölümü, Kayseri, Türkiye (ORCID: 0000-0003-2018-9616) \\ ${ }^{3}$ Boğaziçi Üniversitesi, Biyomedikal Enstitüsü, Biyomedikal Mühendisliği Bölümü, İstanbul, Türkiye (ORCID: 0000-0002-7606-8314)
}

(Konferans Tarihi: 5-7 Mart 2020)

(DOI: 10.31590/ejosat.araconf30)

\begin{abstract}
ATIF/REFERENCE: Orhanbulucu, F., Latifoğlu, F., \& Baş, A. (2020). K-Ortalamalar Kümele Yöntemi Kullanılarak ALS Hastalarında Dikkatin Olaya İlişkin Potansiyel Sinyalleri İle İncelenmesi. Avrupa Bilim ve Teknoloji Dergisi, (Özel Say1), 239-244.

$\ddot{\mathbf{O} z}$

Farklı nörolojik hastalıkların neden olduğu beyinde oluşan anormal durumlar dünya çapında birçok insanı etkilemektedir. Bu anormal durumlardan birisi de Amyotrofik lateral skleroz (ALS)'dur. ALS, beyin sapı adı verilen bölgede motor sinir hücrelerinin zarar görmesiyle ilerleyen fiziksel bozukluklara neden olan genellikle motor nöron hastalığı olarak bilinen bir hastalıktır. Beyin, dışarıdan gelen uyarıları algılar ve algılanan çok sayıda uyarıdan ilgili olanları dikkat mekanizması sayesinde seçer. Dikkat, çeşitli bilgi türlerinin, duygu ve düşünceler gibi aktivitelerin bir bölgeye yoğunlaştııılıp gerekli sürede ilgili uyarıcıların beyin tarafından seçilmesiyle oluşan bilişsel bir süreçtir. Elektroensefalogram (EEG) beynin dikkat mekanizmasında oluşan bu tür aktiviteleri ölçmek ve analiz etmek için önemli bir yere sahiptir. Dikkat analizi için son yıllarda yapılan çalışmalar Olaya İlişkin Potansiyel (OİP) sinyalleri üzerinedir. OIP sinyalleri, EEG sinyallerinde net olarak gözükmeyen P100, N200, P300 ve N400 gibi bileşenlere sahip olan küçük genlikli sinyallerdir. Bu nedenle OİP sinyallerini elde edebilmek için hedef uyaranın tekrarlanması, birçok kez EEG kaydının alınması gerekmektedir. Kayıt alınan hedef uyarana ait EEG sinyallerinin ortalamasının alınması sonucunda OIP sinyalleri elde edilmektedir. Gerçekleştirilen çalışmada, ALS hastaları ile sağlıklı kişilerin OİP sinyallerinden bir takım özelliklerin elde edilip ve görsel uyaranlara karşı dikkat analizinin k-ortalamalar kümeleme yöntemi ile incelenmesi amaçlanmıştır. K-ortalamalar kümeleme yöntemi ile yapılan inceleme sonucunda veriler 2 kümeye ayrılmış ve en yüksek başarı oranı \%77.78 olarak hesaplanmıştır.
\end{abstract}

Anahtar Kelimeler: Dikkat, amyotrofik lateral skleroz, k-ortalamalar kümeleme yöntemi, olaya ilişkin potansiyel sinyalleri, elektroensefalogram.

\section{Analysis of Attention to Potential Signals of ALS Patients by Using the K-Means Clustering Method}

\begin{abstract}
Abnormal conditions occurring in the brain caused by different neurological diseases affect many people worldwide. One of these abnormal conditions is Amyotrophic lateral sclerosis (ALS). ALS is a disease commonly known as motor neuron disease, which causes physical disorders in the area called brainstem, caused by damage to motor nerve cells. The brain perceives the stimuli coming from the outside and selects the related ones from the many perceived stimuli through its attention mechanism. Attention is a cognitive process that is formed by concentrating various types of information, activities such as emotions and thoughts to a region and selecting the relevant stimulants by the brain in the required time. The Electroencephalography (EEG) has an important place to measure and analyze such activities occurring in the brain's mind. Recent studies for attention analysis are on Event-Related Potential (ERP) signals. ERP signals are small amplitude signals with components such as P100, N200, P300 and N400, which are not clearly visible in EEG signals.
\end{abstract}

\footnotetext{
* Bu makale International Conference on Access to Recent Advances in Engineering and Digitalization (ARACONF 2020) de sunulmuştur.

** Sorumlu Yazar: İnönü Üniversitesi, Mühendislik Fakültesi, Biyomedikal Mühendisliği Bölümü, Malatya, Türkiye, ORCID: 0000-0003-4558-9667, firat.orhanbulucu@inonu.edu.tr
} 
For this reason, in order to obtain the ERP signals, the target stimulus must be repeated and EEG recording must be obtained many times. As a result of averaging the EEG signals of the recorded target stimulus, ERP signals are obtained. In the study carried out, it was aimed to obtain some features from the ERP signals of ALS patients and healthy people and to analyze attention analysis against visual stimuli using the $\mathrm{k}$-means clustering method. As a result of the examination made with the K-averages clustering method, the data were divided into 2 clusters and the highest success rate was calculated as $77.78 \%$.

Keywords: Attention, amyotrophic lateral sclerosis, k-means clustering method, event related potential signals, electroencephalogram.

\section{Giriş}

Farklı nörolojik hastalıkların neden olduğu beyinde oluşan anormal durumlar dünya çapında birçok insanı etkilemektedir. Bu anormal durumlardan birisi de Amyotrofik lateral skleroz (ALS)'dur. ALS, beyin sapı adı verilen bölgede motor sinir hücrelerinin zarar görmesiyle ilerleyen fiziksel bozukluklara neden olan genellikle motor nöron hastalığı olarak bilinen bir hastalıktır. Hastalığın ilerlemesi ile ALS'li insanlar tamamen felç olabilir ve genellikle solunum yetmezliği sonucu ölümle sonuçlanabilir [1]. Beyin, dışarıdan gelen uyarıları algılar ve algılanan çok sayıda uyarıdan ilgili olanları seçer. Beyindeki dikkat mekanizması sürekli olarak dış çevreden uyaran alma, dış çevreden gelen uyaranları seçme ve dikkatin devam etmesi adımları ile açıklanabilir. Dikkat çeşitli bilgi türleri, duygu ve düşüncelerinin bir bölgeye yoğunlaştırılıp gerekli sürede ilgili uyarıcıların beyin tarafından seçilmesiyle oluşan bilişsel bir süreçtir [2]. Elektroensefalogram (EEG) beynin bu tür aktivitelerini ölçmek ve analiz etmek için önemli bir yere sahiptir.

Dikkat uzun süredir çeşitli yollarla analiz edilmektedir. Son yıllarda dikkat üzerine yapılan çalışmalar Olaya İlişkin Potansiyel (OİP) sinyalleri ile dikkat analizidir. OİP sinyalleri özel bir aktivite için nöronlar üzerinden yapılandırılmış aktiviteyi gösteren genellikle çok küçük genlikli sinyallerdir ve EEG sinyalinde gözükmezler. Bu nedenle, aynı uyaranın tekrarlanmasıyla ve birçok kez EEG kaydı alarak bu kayıt alınan sinyallerin ortalamasının alınmasıyla ortaya çıkan sinyallerdir [3, 4]. OİP sinyallerinin bileşenleri P100, N200, P300, N400 gibi sinyallerdir. P300, beynin dikkat çeken bir uyaranla uyarıldığı zaman genellikle 300. Milisaniye 'den (ms) sonra oluşan ve 800 ms'ye kadar dağılım gösteren pozitif bir dalgadır [5, 6]. Sutton ve arkadaşları P300'ü ilk olarak yayınlayan kişilerdir [7]. N200 ise beyin uyarıldıktan yaklaşık 200.ms'den sonra görülen negatif bir dalgadır [8].

Literatürde yapılan bazı çalışmalar incelendiği zaman dikkat düzeyinin belirlenmesinde OİP sinyalleri incelenerek objektif sonuçlar bulunmuştur. Güven ve arkadaşları yaptıkları çalışmada kişilere işitsel ve görsel uyaranları farklı zamanlı farklı Oddball uyaran sistemi ile uygulamış ve uyaran sistemleri için ayrı ayrı kayıtlar almıştır. Görsel ve işitsel uyaranlarda frontal (Fz), parietal $(\mathrm{Pz})$, oksipital $(\mathrm{Oz})$ ve santral $(\mathrm{Cz})$ bölgede P100 dalgasının genlik ve latans durumlarını incelemiş, anlamlı bir farklılık elde edememişlerdir [9]. Batbat ve arkadaşlarının yaptıkları çalışmada üniversite öğrencisi gençlerde dikkat tiplerini belirlemek amacıyla işitsel uyaranlar üzerine dikkat tespiti sınıflandırma yöntemleri ile gerçekleştirmiştir. Yaptıkları çalışmada OİP bileşenlerinden P300 dalgasını incelemişlerdir. Ayrık Dalgacık Dönüşümü ile filtrelenen OİP bileşenlerinden P300 dalgasının Latans ve genlik değerlerinin yanında dalgacık katsayı entropi değerleri özellik olarak incelenmiş ve yapılan sınıflandırma işleminde Destek Vektör Makinelerinin en başarılı sınıflandırmayı yaptığı görülmüştür [10]. Yapılan çalışmalar genel anlamda sinyallerin zaman ekseninde OİP bileşenlerinin (P100, N200, P300 vb.) latans ve genlik bilgilerinin değerlendirilmesi şeklindedir [11]. Frekans ekseninde değerlendirme olarak yapılan çalışmalar incelendiği zaman ise OİP sinyallerinin frekans ekseninde değerlendirildiği çalışmalar EEG'nin frekans bileşenlerinin incelenmesi şeklindedir [12]. OİP sinyallerinin tek başına değerlendirilmediği çalışmalar incelendiğinde ise Rupom ve arkadaşları yaptıkları çalışmada ALS hastaları ile sağlıklı kişileri OİP sinyalleri ile birlikte ham EEG sinyallerini de ele almıştır. EEG sinyallerini Alfa ve Beta dalgalarında genlik değerleri bakımından incelemiş ve kullandıkları tekniğin ALS'nin saptanmasına yardımıı olabileceğini önermişlerdir [13].

Yapılan çalışmanın amacı ALS hastası kişiler ile sağlıklı kişilerin OİP sinyallerinden bilinen temel özelliklerin elde edilmesi ve görsel uyaranlara karşı dikkatin k-ortalamalar kümeleme yöntemi ile tespit edilmesidir.

\section{Materyal ve Metot}

\subsection{Veri Seti ve Deney Aşaması}

Bu çalışmada kullanılan EEG sinyalleri herkese açık erişimde sunulan "bnci-horizon-2020" web sitesinde yayınlanan IRCCS Fondazione Santa Lucia (Roma/İtalya) BCI laboratuvarında kaydedilen ve “. mat" formatında verilmiş olan veri kümesinden oluşturulmuştur [14]. Verilerin indirme linki ve gerekli bütün açıklamalar "bnci-horizon-2020" web sitesinde mevcuttur.

Verilerin kaydı sırasında elektrotlar standart 10-10 sistemine göre dizilmiş [15], elektrotların empedansları $10 \mathrm{kOhm}$ değerini aşmayacak şekilde ayarlanmıştır ve 8-16 kanaldan ('Fz, Cz, Pz, Oz, PO7, PO8, FCz, CPz, C3, C4, F3, F4, P3, P4, CP3, CP4') $\mathrm{Ag} / \mathrm{AgCl}$ referans elektrot kullanılarak elde edilmiştir. EEG sinyalleri g.USBamp amplifikatörü (g.MOBILAB, g.Tec, Austria) kullanılarak $256 \mathrm{~Hz}$ örnekleme frekansıyla yaş ortalaması $(58 \pm 12)$ olan 8 ALS hastası kişiden ve yaş ortalaması (26.8 \pm 5.6$)$ olan ALS hastası olmadığı tespit edilen 10 sağlıklı kişiden ölçüm alınarak elde edilmiştir. Verileri toplama ve görsel uyarı işlemleri BCI2000 yazılımı ile gerçekleştirilmiştir [16-18]. Deneklere $6 \times 6$ tipindeki matris içerisinde rakam, harf ve bir takım özel işaretlerin bulunduğu eğitim seti sunulmuştur. Her uyaranın bir satır veya sütunda gösterilme zamanı ve bir uyarıcının bitimi ile kendisini izleyen uyarıcının başlangıcı arasındaki süre (Inter Stimulus Interval-ISI) 125 ms'dir. Bir uyaranın başlangıcı ile diğer uyaranın başlangıcı arasındaki zaman aralığı (Stimulus Onset Asynchrony-SOA) 250 ms'dir. Hedef uyaranların birbirine karışmaması için hedef-hedef arasındaki süre en az 500 ms olacak şekilde ayarlanmıştır. Deneyden önce deneğe odaklanması gereken karakterler söylenmiştir. Örneğin, odaklanılması gereken karakter $\mathrm{O}$ ise $\mathrm{O}$ ’yu içeren 3.satır veya 3.sütunun yanması durumunda hedef uyaran gerçekleşmiş 
olacaktır. Deney aşamasında kullanılan örnek eğitim seti Şekil 1'de görülmektedir. Hedef karakterler matris üzerinde rastgele satır veya sütunda 2 kez gösterilmiş ve birçok kez tekrarlanmıştır [16, 17]. Hedef uyaran için 500 adet içerisinde OİP bileşeni olan EEG sinyali seçilmiştir ve toplam 3000 adet içerisinde OİP bileşeni olan ya da olmayan EEG sinyali ele alınmıştır. Hedef uyaranların gösterilme olasılığı \%16.67 olacak şekilde ayarlanmıştır.
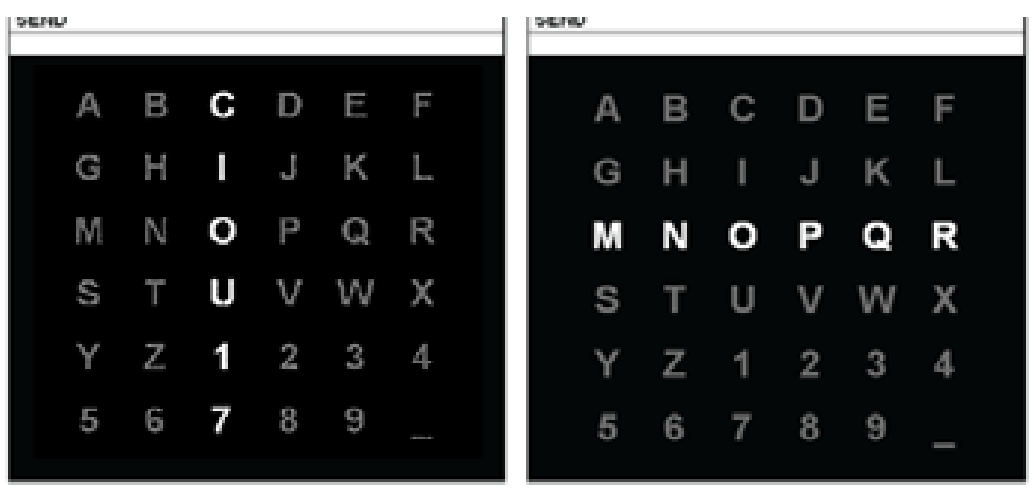

\section{2. Ön İşleme ve Özellik Çıkarımı}

Şekil 1. Ë̆itim seti [19]

Bu çalışmada, EEG sinyallerinin içerisinde gömülü vaziyette olan küçük genlikli OİP sinyalini elde edebilmek için EEG'den hedef uyaranlara ait sinyaller çekilmiş ve benzer çalışmalarda kullanılan her bir hedef uyarana ait sinyallerin ortalaması alınmıştır (Şekil 1). Filtreleme işlemi olarak sinyalde oluşabilecek rastgele gürültüleri azaltmak, sinyalde oluşabilecek dalgalarda ani yükselme ya da düşme durumlarını engellemek ve N200, P300 dalgalarını net elde edebilmek için hareketli ortalama filtre kullanılmış, 0-800 ms aralıklı pencerelere ayrılarak OİP sinyalleri elde edilmiştir (Şekil 2). P300 dalgası için genlik ve latans değerleri, P300 genişliği, N200 dalgası için genlik ve latans değerleri, OİP sinyali üzerindeki tepe sayısı ile OİP sinyalinde tepeden tepeye genlik değerleri özellik olarak incelenmiştir.
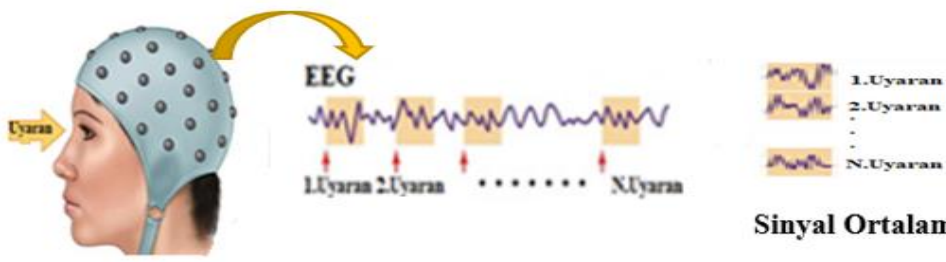

Sinyal Ortalaması

Şekil 2. EEG sinyalinden hedef uyaranların çekilmesi [20]

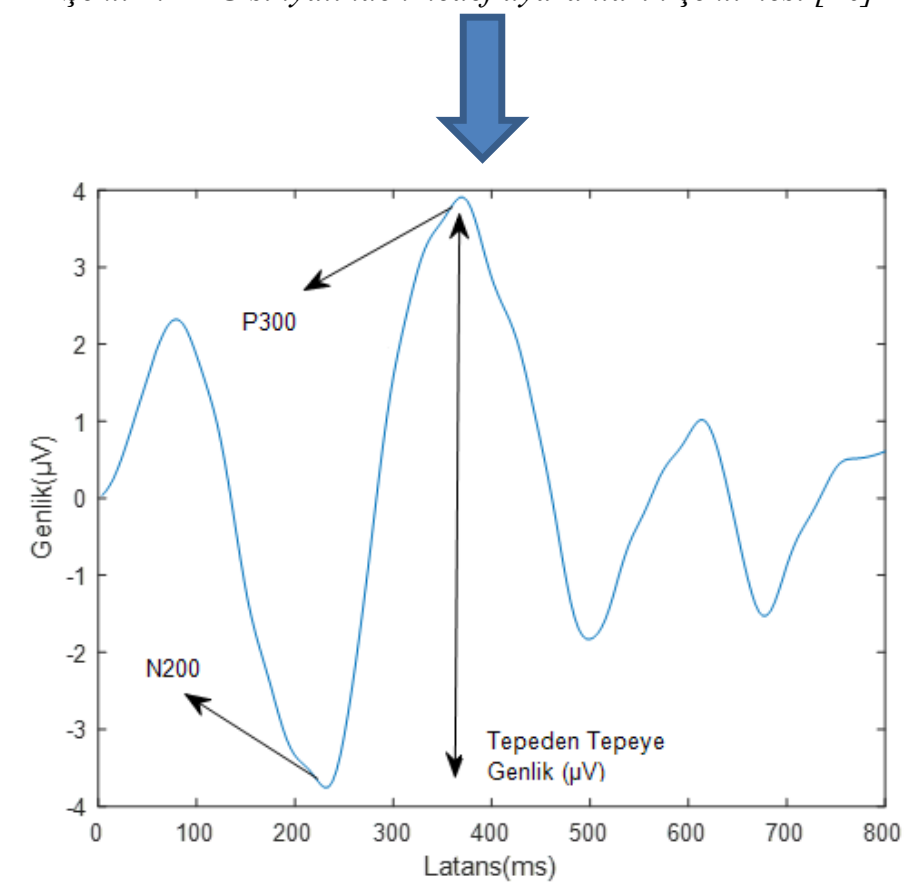

Şekil 3. Hedef uyaranların ortalaması alınarak elde edilen filtrelenmiş OIP sinyali 


\section{Araştırma Sonuçları ve Tartışma}

\section{1. İstatiksel Analiz ve Özellik Seçimi}

Yapılan çalışmada kullanılacak olan özellikler kümeleme işlemine tabi tutulmadan önce aşamalı bir inceleme sürecinden geçirilmiş ve R dili kullanılarak gerekli testleri yapılmıştır. Ele alınan özellikler \%95 güven aralığında Shapiro-Wilk normallik testi ile incelenmiştir. İnceleme sonucunda veriler normal dağılım göstermediğinden dolayı parametrik olmayan testlerden Mann-Whitney U testi uygulanmıştır ve anlamlı fark oluşturan özellikler tespit edilmiştir ( $\mathrm{p}<0.05)$. P300 dalgası benzer çalışmalarda olduğu gibi [10, 11] belirgin olarak gözüken Fz, Cz, Pz kanallarında incelenmiştir. N200 dalgası ise benzer çalışmalarda olduğu gibi oksipital bölgede daha belirgin görülmüş̧ür [21, 22] ve yapılan çalışmada Oz, PO7 ve PO8 kanallarında incelenmiştir (Şekil 3). Çalışmada anlamlı fark oluşturan P300 özellikleri; Pz kanalına ait genlik ve latans değerleri, $\mathrm{Cz}$ kanalına ait genlik değerleri, Fz kanalına ait latans değerleridir. Çalışmada anlamlı fark gösteren N200 özellikleri ise; Oz kanalına ait latans değerleri, PO7 ve PO8 kanalına ait genlik ve latans değerleridir. P300 genişliği, tepeden tepeye genlik değerleri ve OİP sinyali üzerindeki tepe sayısında anlamlı farklılık görülmemiştir.

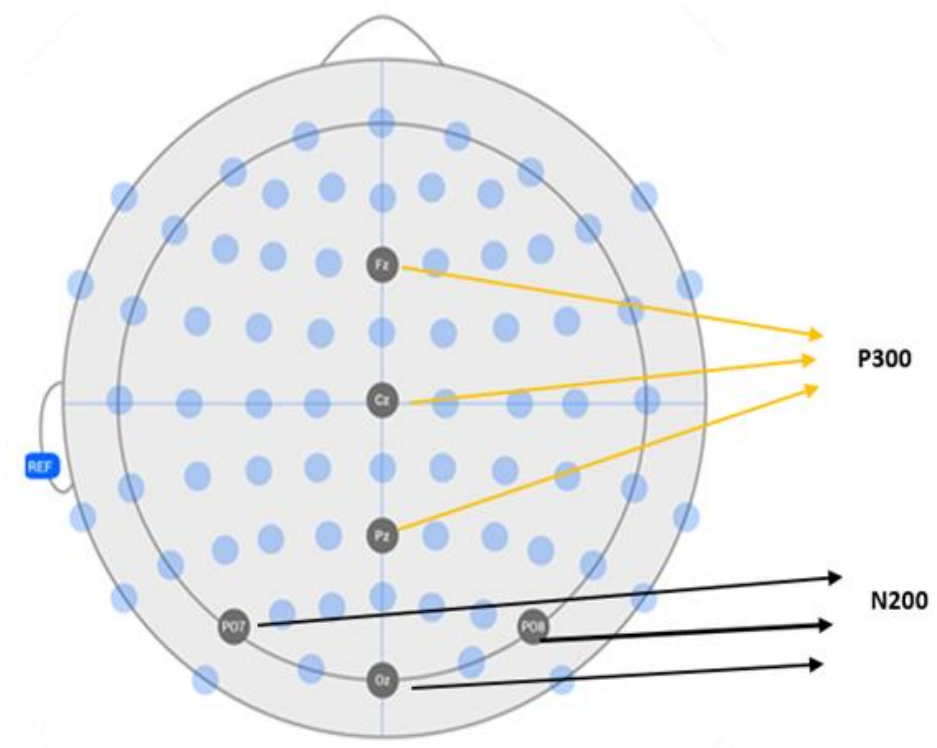

Şekil 4. Çalışmada incelenen kanalların elektrot pozisyonu

\subsection{K-Ortalamalar Kümeleme Yöntemi}

K-ortalamalar kümeleme yöntemi örnekleri kümelerken küme içi benzerliklerin maksimum ve kümeler arası benzerliklerin minimum olmasını sağlamaktadır. K-ortalamalar kümeleme yönteminin fonksiyonu (1) numaralı eşitlikte gösterilmiştir.

$f=\sum_{j=1}^{k} \sum_{i=1}^{n}\left\|\mathrm{x}_{i}^{(j)}-\mathrm{c}_{j}\right\|^{2}$

(1) numaralı eşitlikte belirtilen $\mathrm{f}$, yöntemin fonksiyonunu; $\mathrm{j}=(1,2,3 \ldots \mathrm{k})$ küme sayısını; $\mathrm{i}=(1,2,3 \ldots \mathrm{n})$ örnek sayısını; $\mathrm{c}_{j}$, $\mathrm{j}$. kümenin merkezini temsil ederken, $x_{i}$ örneğin boyut olarak yerini temsil etmektedir. K-ortalamalar kümeleme yöntemi uygulanırken $n$ adet örnek k adet kümeye ayrılır, kümelerin merkezi rastgele seçilir ve öklid uzaklık fonksiyonu kullanılarak örnekler yakınlığına göre küme merkezine etiketlenir. Her küme içerisindeki örneklerin ortalaması alınarak merkezler yeniden belirlenir ve bu süreç merkezler sabit kalana kadar tekrarlanır [23].

\section{Sonuç}

$\mathrm{Bu}$ çalışmada ALS hastası kişiler ile sağlıklı kişilerin görsel uyaranlar üzerine dikkat analizi OİP sinyallerinden elde edilen özellikler ile R dilinde 2 kümeye ayrılarak k-ortalamalar kümeleme yöntemi ile incelenmiştir. K=2 için, 1.kümede sağlıklı kişilerin, 2.kümede ise ALS hastası kişilerin yoğun olarak dağılım gösterdiği görülmüştür. P300 özellikleri tek başına ele alındığı zaman 3 adet ALS hastası, 2 adet sağlıklı kişinin hatalı kümelendiği görülmüştür ve başarı oranı \%72.22 olarak hesaplanmıştır (Şekil 3). P300 özelliklerine ek olarak N200 özelliklerinin de ele alınmasıyla birlikte P300 özellikleri ile hatalı kümelenen 1 adet ALS hastasının doğru kümeye dâhil olduğu, başarı oranının arttığı gözlemlenmiştir ve başarı oranı \%77.78 olarak hesaplanmıştır (Şekil 4). Sonuçlar 2 boyuta indirgenerek görselleştirilmiştir. 


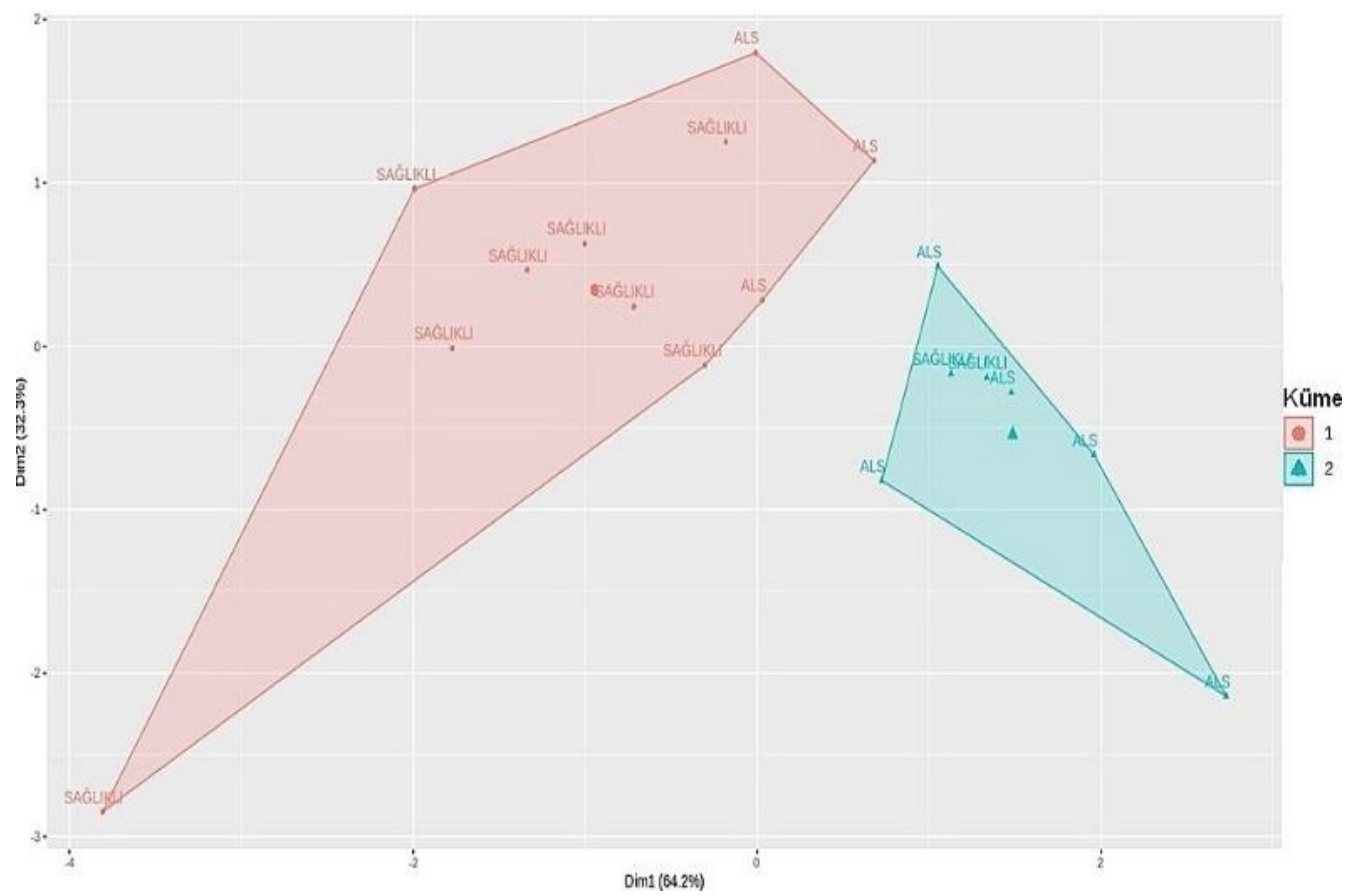

Şekil 5. P300 özellikleri kullanılarak $k=2$ için kümeleme sonucu

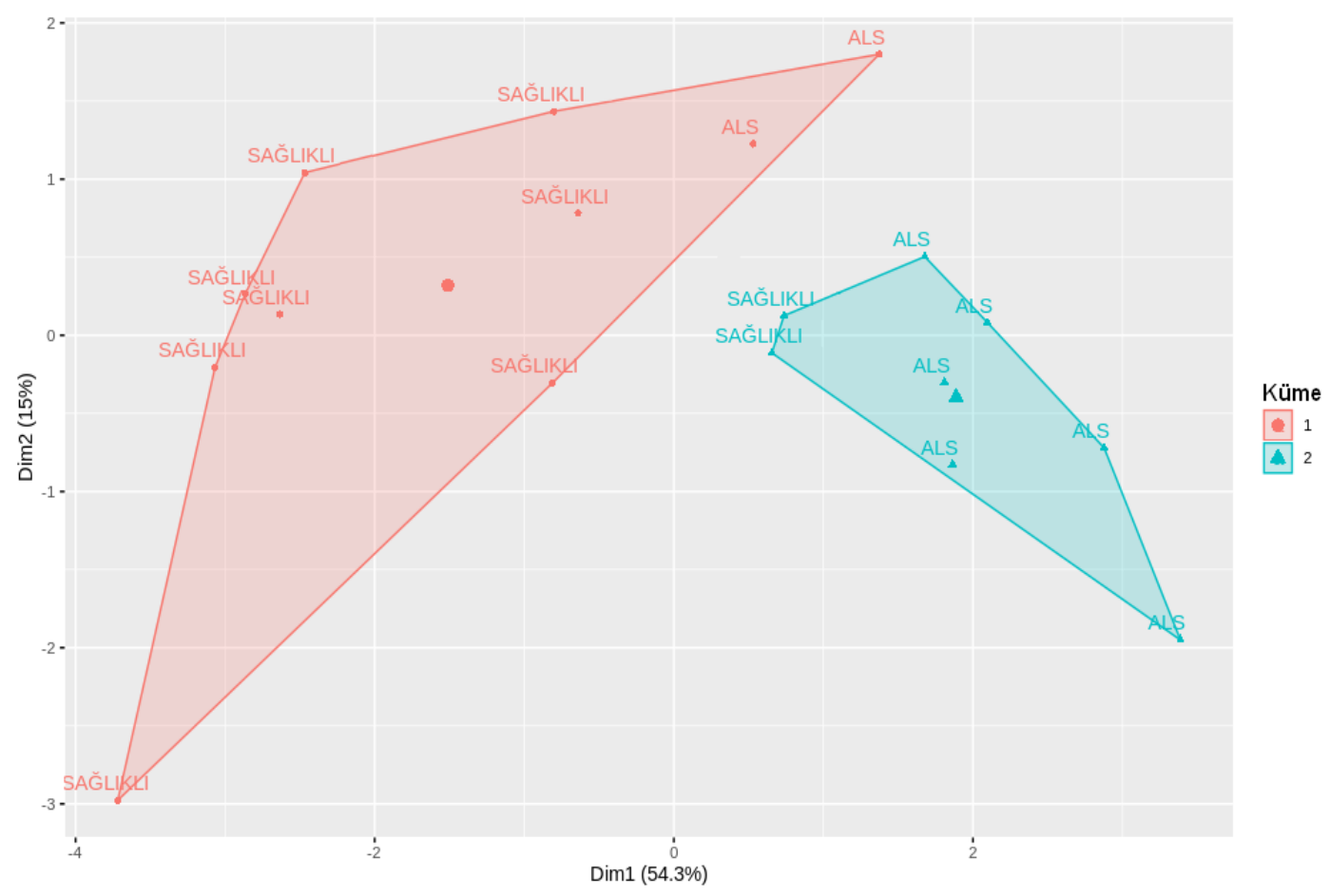

Şekil 6. P300 özelliklerine ek olarak N200 özellikleri dâhil edilmiş $k=2$ için kümeleme sonuçları

[21], [22], [24], [25] referansları incelendiği zaman P300 ve N200 arasında güçlü bir ilişki olduğu ve görsel uyaranlar incelemelerinde N200 dalgalarının P300 dalgası ile birlikte kullanılabilirliği önerilmiştir. Yapılan çalışmada görsel OİP sinyallerinde özellik olarak daha çok ele alınan P300 özelliklerine ek olarak N200 özelliklerinin de kullanılması sonucunda kümeleme başarı oranının arttığı gözlemlenmiş ve yapılan çalışma benzer çalışmalardaki önerileri desteklemiştir. Çalışmanın ilerleyen aşamalarında bu çalışmadan elde edilen sonuçlar kullanılarak çeşitli sınıflandırma yöntemleri uygulayarak ALS hastalığının sınıflandırılması planlanmaktadır. 


\section{Kaynakça}

[1] Oliveira, A. S. B., \& Pereira, R. D. B. (2009). Amyotrophic lateral sclerosis (ALS): three letters that change the people's life. For ever. Arquivos de neuro-psiquiatria, 67(3A), 750-782.

[2] Irak, M., \& Karakaş, S. (2000). Dikkatin beynin nöroelektrik tepkilerine etkisi. Psikiyatr. Psikol. Psikofarmakol. Derg, 8(3), 182-197.

[3] Smith, R. C. (2004). Electroencephalograph based brain computer interfaces (Doctoral dissertation, University College Dublin).

[4] Teplan, M. (2002). Fundamentals of EEG measurement. Measurement science review, 2(2), 1-11.

[5] Ceylan, M.E. (2002) Araştırma ve Klinik Uygulamada Biyolojik Psikiyatri Şizofreni, 1.cilt, 2. bask1, İstanbul $347-350$

[6] Coles, M. G., Smid, H. G., Scheffers, M. K., \& Otten, L. J. (1995). Mental chronometry and the study of human information processing.

[7] Sutton, S., Braren, M., Zubin, J., \& John, E. R. (1965). Evoked-potential correlates of stimulus uncertainty. Science, 150(3700), 1187-1188.

[8] Dennis, T. A., \& Chen, C. C. (2007). Neurophysiological mechanisms in the emotional modulation of attention: the interplay between threat sensitivity and attentional control. Biological psychology, 76(1-2), 1-10.

[9] Güven, A., Dolu, N., Batbat, T., \& Demir, M. (2015). Farklı Dikkat Durumlarının Uyarılmış Potansiyeller Üzerine Etkisinin P100 Dalgası ile Analizi Analysis of the Effect of Different Attention Types on Evoked Potentials by P100 Wave. Tiptekno'15, 15(18), 197-200.

[10] Batbat, T., Güven, A., Dolu, N., \& Demir, M. Farklı Dikkat Tiplerinin Uyarılmış Potansiyeller İle Sınıflandırılması Classification of Different Attention Types With Evoked Potentials. Tiptekno2016, ss.106-109

[11] Güven, A., Dolu, N., Batbat, T., \& Demir, M. (2015). İşitsel ve görsel uyaranların bölünmüş dikkate etkisinin P300 dalgası ile analizi. Ulusal Fizyoloji Kongresi, Çanakkale.

[12] Chang, C. F., Liang, W. K., Lai, C. L., Hung, D. L., \& Juan, C. H. (2016). Theta oscillation reveals the temporal involvement of different attentional networks in contingent reorienting. Frontiers in human neuroscience, 10, 264.

[13] Rupom, A. I., \& Patwary, A. B. (2019, February). P300 Speller Based ALS Detection Using Daubechies Wavelet Transform in Electroencephalograph. In 2019 International Conference on Electrical, Computer and Communication Engineering (ECCE) (pp. 1-5). IEEE.

[14] BNCI Horizon 2020 website. [Online]. Available: http://bnci-horizon 2020.eu/database/data-sets

[15] Jurcak, V., Tsuzuki, D., \& Dan, I. (2007). 10/20, 10/10, and 10/5 systems revisited: their validity as relative head-surface-based positioning systems. Neuroimage, 34(4), 1600-1611.

[16] Aricò, P., Aloise, F., Schettini, F., Salinari, S., Mattia, D., \& Cincotti, F. (2014). Influence of P300 latency jitter on event related potential-based brain-computer interface performance. Journal of neural engineering, 11(3), 035008.

[17] Riccio, A., Simione, L., Schettini, F., Pizzimenti, A., Inghilleri, M., Olivetti Belardinelli, M., \& Cincotti, F. (2013). Attention and P300-based BCI performance in people with amyotrophic lateral sclerosis. Frontiers in human neuroscience, 7, 732.

[18] Schalk, G., McFarland, D. J., Hinterberger, T., Birbaumer, N., \& Wolpaw, J. R. (2004). BCI2000: a general-purpose braincomputer interface (BCI) system. IEEE Transactions on biomedical engineering, 51(6), 1034-1043.

[19] Farwell, L. A., \& Donchin, E. (1988). Talking off the top of your head: toward a mental prosthesis utilizing event-related brain potentials. Electroencephalography and clinical Neurophysiology, 70(6), 510-523.

[20] San Martin, R., \& Huettel, S. A. (2013). Cognitive functions as revealed by imaging of the human brain. Neuroscience in the 21st century, 2213-2238.

[21] Jin, J., Sellers, E. W., Zhou, S., Zhang, Y., Wang, X., \& Cichocki, A. (2015). A P300 brain-computer interface based on a modification of the mismatch negativity paradigm. International journal of neural systems, 25(03), 1550011.

[22] Folstein, J. R., \& Van Petten, C. (2008). Influence of cognitive control and mismatch on the N2 component of the ERP: a review. Psychophysiology, 45(1), 152-170.

[23] Xu, R., \& Wunsch, D. (2005). Survey of clustering algorithms. IEEE Transactions on neural networks, 16(3), 645-678.

[24] Karagöz, M., Alkaç, Ü.İ., Ergen, N., Eradamlar, N., \& Alpkan, 1. (2005). Majör Depresyonda Elektrofizyolojik (P300) Yöntemler. Düşünen Adam, (18), 120-128.

[25] Riccio, A., Schettini, F., Simione, L., Pizzimenti, A., Inghilleri, M., Olivetti-Belardinelli, M., Mattia, D. \& Cincotti, F. (2018). On the Relationship Between Attention Processing and P300-Based Brain Computer Interface Control in Amyotrophic Lateral Sclerosis. Frontiers in human neuroscience, 12, 165. 